\title{
Research on Life Cycle Management of PPP Project Assets
}

\author{
Xiaojie Zhou, a, Yilin Yin ${ }^{1,2}$ \\ ${ }^{1}$ Tianjin University of Technology, Tianjin, 300384, China \\ ${ }^{2}$ Department of Management and Economics, Tianjin University, Tianjin, 300072, China \\ a Email: 1597577993@qq.com
}

Keywords: PPP project; asset management; ALM model; life cycle

\begin{abstract}
The formation of PPP project assets has a direct bearing on the public interest. Based on the theory of public goods and the new public management movement model, by analyzing the existing problems in various stages of PPP projects and using the ALM model to construct the life cycle management framework of PPP project assets, to link the various stages of the PPP project closely, the PPP project's asset management will be carried out from a new perspective.
\end{abstract}

\section{Introduction}

Since 2014, many national ministries and commissions, especially the Ministry of Finance and the National Development and Reform Commission have successively promulgated several related documents to promote the government and social capital cooperation (PPP) model, which has created an upsurge of PPP in China. PPP project assets are directly related to public interests, and the problems or difficulties encountered at various stages of the PPP project make the government want to create the greatest public interest, together with private capital to increase the efficiency of public goods supply, that is, the desire to ensure maximum welfare and efficiency is defeated. Therefore, how to correctly manage the PPP project assets from the perspective of the entire life cycle of the project is particularly important. From the perspective of asset life cycle management, this paper will plan the phases of planning, construction, operation, maintenance, and transfer of PPP projects. Under the premise of satisfying the public interest and social capital economic benefits, it will achieve the value stability and improvement of the entire life cycle of PPP project assets.

\section{PPP Model and Project Asset Management}

\subsection{The significance and scope of PPP projects and their assets}

PPP is the English abbreviation of Public Private Partnerships. It is usually translated into a public-private partnership. China's PPP projects have developed rapidly in recent years. The PPP model can be defined as the public and private sectors of the government based on the guarantee of public interest and supply efficiency. By signing relevant agreements to standardize the rights and obligations of both parties, realize risk sharing and benefit sharing, and provide a new partnership partnership model of public goods or services.

PPP projects include infrastructure for transportation, ecological construction and environmental protection, education, water conservancy construction, medical and health, and affordable housing projects. These areas are closely related to the public interest. The satisfaction of stakeholders' needs depends on the realization of the value of the project. For PPP projects, it mainly meets the needs of the government for public goods and services and the needs of the private sector for the pursuit of benefits.

PPP projects are invested, constructed and operated by fixed assets by the government and social capital. The ultimate ownership of the assets belongs to the country. The government uses these assets to engage in the provision of public goods or services to promote the growth of public interests, and social capital uses these assets to achieve its own economic interests. The concept of 
assets is used to study the issues of PPP project assets. On the one hand, it reflects the value forms of PPP projects and emphasizes the concept of value management. On the other hand, the public welfare goals of PPP projects are fully considered, and the economic and social aspects of PPP projects Benefits can be better measured.

\subsection{Methods of project asset management}

\subsubsection{Traditional project asset management methods}

Because of the nature of monopolistic operations of oilfield companies, it is difficult for companies in the petrochemical industry to get rid of the financial management is more closed, financial management and business and the overall management environment of the management of convergence and weaker convergence, so that there are some typical problems that are difficult to fully support scientific decision-making such as poor concept management of assets. Compared with the electric power industry, although the management of fixed assets has been developed into electronic information management, the different software development targets of different companies have also made the efficiency of asset management work much lower. Therefore, as can be seen from the above areas, finding a suitable asset management philosophy and model can not be ignored.

In the construction project, the traditional construction mode forms a fixed asset, which is the separation of design and construction, and the separation of construction and operation. The objectives and interests of different stages are different, lack of overall goal consistency, and lack of communication management, lack of management of the entire process of assets. The emergence of a large number of construction and operation of the PPP model requires the conversion of management concepts and the innovation of management methods. The objectives and tasks of PPP project asset management can no longer satisfy the asset management methods in the traditional situation, and a new management concept and solution are urgently needed.

\subsubsection{Asset life cycle management study}

As the impact of modern industrial activities on the environment has received widespread attention, Asset Lifecycle Management (ALCM) has evolved into a new management approach. For example, Haffejee M and Brent A C proposed the integrated ALCM (Asset Life Cycle Management, ALM, the same below) model of the water sector based on the integration of LCM and asset management theory. Charles A. Schuman and Alan C. Brent proposed the asset life cycle management (ALCM) model for the assets of the processing manufacturing industry. This model combines the concepts and operational reliability of the common project management framework and system engineering and proposes the manufacturing industry. ALCM model.

Through the analysis of domestic literature, some studies have shown that the asset life cycle management is widely used in the research of fixed assets of electric construction companies, and also involves fields such as oil and gas assets. For example, Fachi Chen and Duanhong Guo analyzed and analysed the whole life cycle management system of fixed assets of a power grid company according to the whole life cycle and the problems and reasons at each stage. It was found that the lack of effective supervision in the design stage led to design redundancy, and the construction phase paid attention to the construction cost and ignored the later period. Operational and maintenance costs, lack of effective performance appraisal of assets in the asset operation and maintenance phase leads to a reduction in the availability of assets, and specific improvements and precautions are proposed for these issues. Dan Jian's partial management of the management work caused by the different management of oil and gas oilfield asset management according to the different functions of the oil and gas fields. The rough management of the assets "who uses whom" leads to the problem of inflated assets, "regaining, light flow; reoccupying, light The lack of awareness of asset operations caused by the concept of "effectiveness" and the lack of an effective assessment and assessment mechanism led to the misunderstanding of asset management, and analyzed the specific implementation measures for the entire life cycle of oil and gas assets in oil fields. 
In summary, there is a life-wide asset management method in the industries of processing and manufacturing, power generation and petrochemical smelting. It is designed to solve the problem of redundant design, heavy construction, light operation, inflated assets, and improper government supervision and lack of effectiveness. Performance assessment and other issues arise and develop. This article argues that asset life cycle management (ALM) is actually using assets as the research object. From the perspective of the entire life cycle, it provides comprehensive and full-fledged management of asset generation process, operation protection and application, and considers assets in life. Problems in different stages of the cycle, through the adoption of effective measures to improve the overall efficiency of asset management.

Relevant studies have found that in the process of advancing the PPP model in China, there are also problems of heavy construction light operation and design redundancy, possible asset collapse, lack of effective performance appraisal, and inadequate government supervision, that is, the analysis of the above analysis. Problems or loopholes in the design phase, construction and construction phase, operation and maintenance phase of handover. Then, through the innovative ideas of transplantation, the PPM project asset management and the ALM model will be nested in order to achieve the goals and tasks of PPP project asset management.

\subsection{The objectives and tasks of PPP project asset management}

\subsubsection{PPP project asset management based on public goods theory}

The PPP model is an institutional arrangement for the public sector to cooperate with the private sector in the provision of public goods. It involves the exercise of public power and the protection of public interests and has a significant public nature. The institutional goal of the PPP project is to ensure that the government effectively provides public goods to meet the needs of the public. The public goods theory is an important theoretical foundation that underpins its institutional development. Because the provision of public goods is attached to public projects, the supply of public goods has a direct bearing on the success or failure of public projects. While PPP projects refer to the use of the PPP model to provide public goods or services, which still belong to the category of public projects, the PPP projects form assets. It is necessary to satisfy the government's efforts to achieve the greatest public interest and to ensure that the government provides the public with supply requirements for public goods or quasi-public goods and services.

In the PPP project, the government subsidizes the project or provides supporting facilities and transfers the franchise right of the project to social capital. Therefore, it is necessary to supervise the PPP project effectively, and it is necessary to rationally arrange the formation of the assets in each stage of the life cycle of the PPP project. Determined to strictly implement the specific implementation of the project and follow-up operation transfer in accordance with the requirements of the planning and design stage to ensure accurate production of PPP project assets, improve the supply of public goods, and increase public interest.

\subsubsection{PPP project asset management based on new public management movement}

The new public management movement is a kind of enterprise-based business management model that is used to improve public product management and improve public service quality under the regulation of market competition mechanism. It advocates that the government public sector learn to use the private sector's successful management experience and competitive means to improve the efficiency of public services on the basis of solving public problems and satisfying public needs. It stresses that the government and the public cooperate with lower government operating costs. The public provides the most effective service.

In the PPP project, we can learn from the experience of the "New Public Management Movement." The government should take the initiative to guide private enterprises to actively participate in the supply and service of public goods through cooperation. They should be able to identify their position and use the identity of the "governor" to carry out the asset management of the entire phase of the PPP project from the perspective of the project life cycle.

Based on the theory of public goods and the new public management movement, the nature of 
the PPP project is still government investment projects. Its purpose is still to provide the public with high quality products or services. Therefore, during the entire life cycle, whether in the formation or landing phase, it is necessary to ensure the rational determination and accurate generation of PPP project assets. For example, during the planning and design phase, the emergence of heavy-duty light operation should be avoided, redundant design should be prevented, and excess function should be avoided. During the construction and construction phase, assets should be avoided from being inflated. During the operation and maintenance phase, assets should be preserved and added, and assets should be kept sustainable.

\section{Status Analysis of PPP Project Asset Management}

The traditional sense of asset management mainly refers to the operation, maintenance and repair of physical assets during service. The starting point is to ensure the stable and reliable operation of assets by combining the maintenance management with the perspective of asset reliability. The PPP project asset management described in this paper focuses more on the movement status of the entire asset-related value. It covers the concept of a series of asset life cycles such as preliminary planning and design, mid-term construction and subsequent operation and maintenance handover, and its starting point is the public of the entire PPP project. In order to make the formation of assets more smooth and use more smoothly, only the integration and close connection at all stages can better reflect the value of assets.

\subsection{Planning and design stage}

In the planning and design stage, the preparation and filing of relevant data is the process of asset formation in PPP projects and an indispensable part of asset management. Analyzing the current problems in this stage and identifying the incisions can better solve the problem of PPP project asset management.

In the early planning stage of the PPP project, due to the deep-rooted thought of "construction and light operation" in the traditional construction, the planning requirements for the pre-project were insufficient. With the launch of the PPP project, the two assessment cases in the planning stage reported that the probability of occurrence of similarity appeared in a large area, especially the documents prepared by the same consulting company, and the probability of occurrence was even greater, and some places were conducting "two assessments". At the same time, there are also phenomena that are in a form that deserve attention and prevention. At present, the PPP consulting market is uneven, and some consulting organizations lack professionalism and independence. This has led to the lack of detailed contents and strict requirements in the case of the two assessments, which has caused the formation of the assets of the PPP project to be hindered and urgently needed to be resolved.

The design phase, as a transitional stage between decision-making and construction, is not only an extension of the decision-making phase, but also the basis for whether the PPP project can be built faster and better during the construction phase. The amount of investment in construction projects and whether the delivery after completion can fully realize economic benefits are directly related to the quality and depth of the outcome documents formed at the design stage. Some studies have shown that the design stage has a large proportion of the impact on the cost, and as the project progresses, the degree of impact declines. Therefore, the design phase is critical during the entire life cycle of a project. However, in the design process, there was a simple emphasis on design, forgetting the purpose of design and designing a crisis for design. This kind of crisis is manifested as redundant design and excess functionality.

\subsection{Construction stage}

The construction stage is the generation phase of PPP project generation after the completion of archiving design stage data. This is the stage for the generation of PPP project assets. This stage has a higher requirement for asset management. To ensure the accuracy of the project assets, from the construction project Based on the characteristics of implementation under the PPP model, the 
importance of audit supervision in the PPP project is analyzed, with a view to improving project efficiency under the premise of ensuring public interest.

\subsubsection{Construction period of PPP project}

At present, the PPP project spans a large time span during the main construction period, and its corresponding control is also more difficult, and because of the large number of participants in the PPP project, the internal settlement system is relatively complex, often because of the internal project accounts. The increase in the auditing workload of the traditional final accounts of PPP projects that caused a certain degree of difficulty and risk due to mistakes or false positives. Therefore, it is necessary to establish an audit system that can adapt to PPP project auditing on the basis of current traditional auditing.

\subsubsection{Period of PPP Project Construction Node}

At present, the participation of PPP projects is often at the time of project construction handover and key nodes when the parties are in weak control, which impedes the audit work. At the same time, the construction of PPP projects will be threatened because of the threat of safe handover between project construction materials. Management should strengthen the audit supervision during the handover and node period.

\subsection{Operation and transfer stage}

The performance evaluation and related research involved in the use of PPP project assets play an indispensable role in PPP project asset management. The use of assets occupies an important part in asset management. Therefore, the methods and methods of dealing with it will directly reflect the policies and means of asset management, thereby affecting the efficiency of asset use.

\subsubsection{Performance under the conditions of compliance}

In the PPP project operation and management, due to the heavy construction and light management ideas, the lack of understanding of the PPP project assets during the operation and maintenance phase has caused many places to pay less attention to the management after the completion of the project, leading to extensive project management and poor operation. Many PPP projects have encountered a series of "mess" problems in the state of performance appraisal. For example, due to the government's unscrupulous pursuit of GDP and the emergence of a large number of development areas, such as the relevant government only because of competition and comparisons Is the appearance of flashy airports and roads. The phenomenon of waste is evident in front of a large number of facts, resulting in insufficient utilization of capital. Therefore, establishing a proper management system for PPP project assets makes the government strictly in charge of asset supervision is an integral part of PPP projects.

\subsubsection{Performance under non-compliance}

With the increasing number of PPP projects, new requirements and new tasks have been put forward for the use of PPP project assets. However, at present, some PPP projects still have the concept of "do nothing" management of public services and facilities assets, resulting in the emergence of low asset utilization rates. , also often accompanied by the occurrence of idle assets. Therefore, for the healthy development of the PPP model, building a new type of urbanization in China faster and better and finding a PPP project asset management system that is suitable for China's development path is of utmost importance.

\section{Construction and Application of PPP-ALM Model of PPP Project Asset Lifecycle Management}

\subsection{PPP-ALM model structure}

In 1965, the U.S. Department of Defense began implementing the US military's weapon purchases in its forces. It was one of the earliest activities to manage the entire life cycle of assets. It 
fully considered the problems in various stages of the entire life cycle, and managed the entire life cycle for efficiency. The highest, design feasible and effective measures, and strive to achieve the best technology, the best quality, the fastest progress, the lowest cost, best service, green environmental protection effect.

The whole life cycle management of assets is actually centered on assets, starting from the perspective of the entire life cycle of the asset, aiming at the goal of improving the overall efficiency of assets, and the management method of theory and practice. The proposed PPP-ALM model research technology roadmap is shown in the figure.

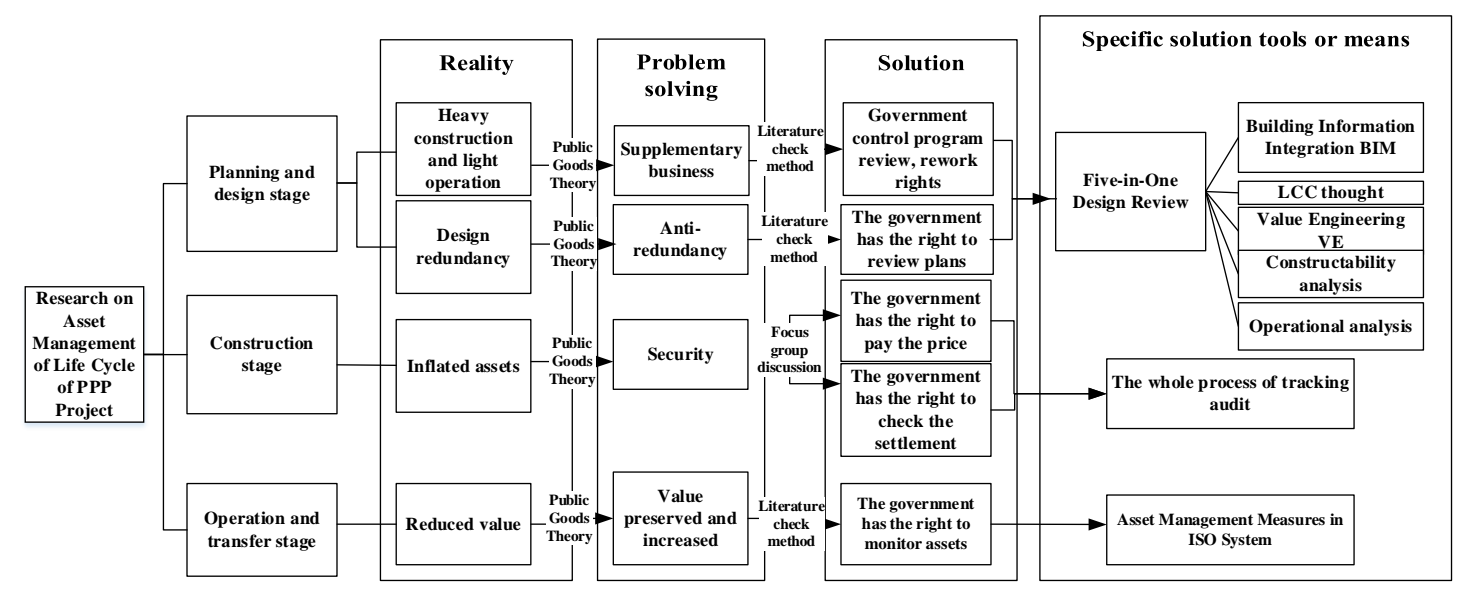

Figure. 1 Research Technology Roadmap

The whole life cycle of PPP assets is divided into three major asset management modules: one is asset planning management with the core of design optimization; second, asset formation process management with core of follow-up audit; and third, asset use and assets with performance monitoring as the core Handover management.

\subsection{Application of PPP-ALM model}

\subsubsection{Planning and Design Phase - Five-in-One Design Review}

(1) Application of LCC in the design stage of PPP project

Life Cycle Costing (LCC) is based on the long-term economic benefits of the project, and fully considers the entire process of planning, construction, and operation and maintenance transfer, so as to minimize the LCC management concept and method.

This paper takes a comprehensive and systematic consideration of the project construction and operation and maintenance phases under the perspective of LCC focusing on the design phase of the PPP project. It analyzes the impact of the project's entire life cycle, including construction and operation and maintenance costs, and selects multiple feasible design options., Through the program comparison, according to the LCC minimum principle, the experts choose the optimal rationalization program.

(2) Application of value engineering in the design stage of PPP projects

However, it should be noted that the LCC minimum cost plan is not necessarily the best overall life cycle plan. By introducing "value engineering" to "function and cost" analysis, the PPP project design plan will be selected and optimized, with reasonable cost. Get reasonable and maximum functions, ensure the effective and reasonable allocation of resources, and meet the concept of full life cycle management, so as to achieve the goal of optimal asset performance of PPP projects.

Specifically, the significance of applying value management in the engineering design phase lies in that the purpose of the application value management in the engineering design phase needs to consider the value orientation of different stakeholders in the project, and it needs to identify the interests appeals of the PPP project stakeholders and In the pursuit of various designs, a compromise solution agreed upon by all parties is sought so that the function and cost of the project can be taken into account in the selection of the design proposal, and the requirements for meeting 
the public needs and improving the public interest can be met.

(3) Application of constructability in the design stage of PPP project

The narrow sense of constructability problems often refer to the inconvenience of construction quality problems in design quality problems, which can be solved by design optimization. However, in a broad sense, it is usually considered from the perspective of the overall construction plan to consider construction requirements such as the overall schedule and the layout of the master plan, which are mainly manifested in the early implementation stage.

Therefore, the issue of constructability in the broad sense is the key to feasibility analysis. By designing for construction services, construction costs can be greatly reduced, and the contractor can be encouraged to further control construction quality and construction progress to achieve the overall value of the project. In architectural design, the flexible use of accumulated drawings and data to achieve the sharing of information can effectively improve the link between design and construction and achieve application of constructability.

(4) Application of BIM in the design stage of PPP project

The design results of the PPP project stage are directly related to the interests of the public interest and social capital. The integrated advantages embodied in the application of BIM enable different stakeholders to solve problems on a unified platform, and design that can be discovered by optimizing the design scheme and reducing the construction period. Errors, thereby shortening the duration and reducing costs. Its application value is mainly reflected in the following four aspects:

(1)Visualization helps external supervision and public participation;

(2)collaborative design to improve the design quality;

(3) Collision check to help prevent PPP risk;

(4) Simulation analysis Optimize public products or services.

\subsubsection{Construction stage}

(1) Deepening the audit content of PPP construction project - tracking the entire process

The audit and supervision from the perspective of the whole life cycle management of PPP project assets can proceed from the height of the project as a whole, and promote the efficiency of PPP projects through systematic audit supervision, and actively improve the project operation. The main supervision contents involved in the audit of different stages of the PPP project are also inconsistent. The difference in the time of intervention will lead to differences in the effect of audit supervision. The earlier intervention of audit supervision can maximize the value of the whole life cycle.

The construction phase is the key phase of putting the results of the planning and design phase into practice and forming the project asset entity. It not only completes the formation of the asset data information, but also provides the basis for the operation and maintenance transfer phase. Due to its unpredictability, the construction process has relatively complicated risk factors. For this reason, the construction phase is a solid guarantee for the realization of PPP project assets. If the management gets out of control, it will lead to the failure of previous work. Starting from the requirements of asset life cycle management objectives, taking PPP project assets as the research object, the method of tracking and auditing in key areas was adopted, focusing on the follow-up audit of contract management, construction process and completion acceptance process in the construction phase of PPP projects.

(2) The main contents of the follow-up audit of the whole process of PPP project

Follow-up auditing is an audit model that distinguishes it from pre-event auditing and post-event auditing. With the beginning of the project construction, the follow-up audit work was immediately launched, and the entire project construction process was firmly grasped so that the limitations of post-event supervision can be effectively controlled.

Auditing of the whole process of follow-up auditing starts from the start of the project until the completion of the construction project, and the entire process of the PPP project is audited and supervised. According to the project construction time, it is divided into four stages, pre-construction pre-construction auditing, inspection of data files according to regulations, 
inspection and supervision of construction quality during the construction period, settlement audit of completed projects, and the financial statement audit after the completion of the project. Under the background of the whole life cycle management, in order to effectively improve the construction efficiency and project quality, the whole process of follow-up auditing can not be ignored.

\subsubsection{Operation and transfer stage}

The management of PPP project assets in the operation and transfer phase is a process of making full use of mixed ownership assets and rational allocation of resources in the process of government and social capital cooperation. Its purpose is to promote the stability and improvement of the operational performance of PPP projects. In the process of practice, "performance appraisal" will be used as a starting point to implement pre-event, intra-event and post-event linkage control to ensure the stability of the value of PPP project assets.

(1) Phase of operation and maintenance of PPP project

The performance evaluation of PPP projects has been focused by government departments and the private sector since the project planning stage. For example, Yanhong Liang and others proposed in the study that there are many cases of failure due to the lack of performance evaluation standards in practice, which indicates that the importance of performance evaluation at different stages of the PPP project according to different needs. However, due to the outstanding characteristics of non-profit, public and other characteristics of PPP projects, project performance evaluation cannot be based on economic benefits alone, and the performance evaluation index system should be selected on the basis of PPP project performance evaluation target positioning, which is conducive to realizing project assets. The use of efficiency is maximized to ensure the preservation and appreciation of PPP project assets. At the same time, in order to ensure a comprehensive evaluation from an objective perspective, the establishment of evaluation indicators must follow certain rules:

(1)The principle of combining comprehensiveness and simplicity;

(2)The principle of combining theory with practice;

(3) The principle of combination of objectivity and integrity;

(4)the principle of integration of integrity and guidance;

(5)The combination of quantitative analysis and qualitative analysis;

(6)The principle of combining normative and impartiality.

(2) Transfer stage of PPP project

Noted that most PPP projects will eventually need to transfer their project assets and franchise rights. This requires a pre-determined procedure for the transfer of assets in the PPP contract, a good preparation for transfer, a good contractual transfer clause, and a good asset assessment standard. It lays the foundation for the smooth transfer of PPP project assets. The main purpose is to clarify the property rights of the project assets, assess whether the assets can continue to operate in accordance with the agreed transfer standards, etc. The use value or the determination of safety and environmental hazards should also be clearly defined at the time of transfer. From the PPP project assets life cycle management system, do a good job of escorting the project transfer.

\section{Conclusions}

From the perspective of the project implementation agency, this paper uses the ALM model to construct a life cycle management framework for PPP project assets. In the PPP project design phase, there exist problems such as redundant design, excess functionality, lack of assets in the construction phase, and insufficient efficiency in the operational phase. From the perspective of the full life cycle, the PPP project's planning and design phase, construction phase, operation and maintenance and handover phases are specifically analyzed. The government achieves reasonable control and management of assets through design optimization, follow-up audit of the entire construction process, and strict supervision during the operation phase. It will greatly promote the 
implementation and promotion of the PPP model in China and is of great significance to the development of PPP projects.

\section{References}

[1] Haffejee M,Brent A C.Evaluation of an integrated asset life-cycle management(ALCM) model and assessment of practices in the water utility sector[J].Applied Microbiology \& Biotechnology,2008,34(2):766-773.

[2] Charles A.Schuman,Alan C.Brent.Asset life cycle management: towards improving physical asset performance in the process industry[J].International Journal of Operations \& Production Management,2005,25(6):566-579.

[3] Shouwen Zhang. The Public Nature of PPP and Analysis of Its Economic Law [J]. Law, 2015(11).

[4] Yanhong Liang, Hongjun Jia, Yanxia Liu. An Empirical Study on Performance Evaluation Criterion of Continuous Improvement of PPP Projects [J]. Construction economy, 2017(10):52-58. 